\title{
Sleep Spindle Density Predicts the Effect of Prior Knowledge on Memory Consolidation
}

\author{
Nora Hennies, ${ }^{1,2}$ Matthew A. Lambon Ralph, ${ }^{1}$ Marleen Kempkes, ${ }^{1}$ James N. Cousins,,${ }^{1,3}$ and Penelope A. Lewis ${ }^{1,4}$ \\ ${ }^{1}$ Neuroscience and Aphasia Research Unit, School of Psychological Sciences, University of Manchester, Manchester M13 9PL, United Kingdom, \\ ${ }^{2}$ Department of Systems Neuroscience, University Medical Center Hamburg-Eppendorf, 22303 Hamburg, Germany, ${ }^{3}$ Cognitive Neuroscience Laboratory, \\ Duke-National University of Singapore Graduate Medical School, Singapore 169857, and ${ }^{4}$ School of Psychology, Cardiff University, Tower Building, 70 Park \\ Place, Cardiff CF10 3AT, United Kingdom
}

Information that relates to a prior knowledge schema is remembered better and consolidates more rapidly than information that does not. Another factor that influences memory consolidation is sleep and growing evidence suggests that sleep-related processing is important for integration with existing knowledge. Here, we perform an examination of how sleep-related mechanisms interact with schema-dependent memory advantage. Participants first established a schema over 2 weeks. Next, they encoded new facts, which were either related to the schema or completely unrelated. After a $24 \mathrm{~h}$ retention interval, including a night of sleep, which we monitored with polysomnography, participants encoded a second set of facts. Finally, memory for all facts was tested in a functional magnetic resonance imaging scanner. Behaviorally, sleep spindle density predicted an increase of the schema benefit to memory across the retention interval. Higher spindle densities were associated with reduced decay of schema-related memories. Functionally, spindle density predicted increased disengagement of the hippocampus across $24 \mathrm{~h}$ for schema-related memories only. Together, these results suggest that sleep spindle activity is associated with the effect of prior knowledge on memory consolidation.

Key words: memory consolidation; prior knowledge; schema; sleep; spindles

\section{Significance Statement}

Episodic memories are gradually assimilated into long-term memory and this process is strongly influenced by sleep. The consolidation of new information is also influenced by its relationship to existing knowledge structures, or schemas, but the role of sleep in such schema-related consolidation is unknown. We show that sleep spindle density predicts the extent to which schemas influence the consolidation of related facts. This is the first evidence that sleep is associated with the interaction between prior knowledge and long-term memory formation.

\section{Introduction}

The assimilation of new information into existing knowledge is essential for long-term memory formation. Evidence from ro-

Received Aug. 22, 2015; revised Feb. 1, 2016; accepted Feb. 23, 2016.

Author contributions: N.H., M.A.L.R., and P.A.L. designed research; N.H. and M.K. performed research; N.H., M.A.L.R., J.N.C., and P.A.L. analyzed data; N.H., M.A.L.R., and P.A.L. wrote the paper.

This work was supported by the Biotechnology and Biological Sciences Research Council (Grant BB/F01760X/1) and a New Investigator award (BB/F003048/1) to P.A.L., and by the University of Manchester. We also thank staff at the Magnetic Resonance and Image Analysis Reseach Centre, Liverpool University's neuroimaging centre, for their technical support.

The authors declare no competing financial interests.

This article is freely available online through the J Neurosci Author Open Choice option.

Correspondence should be addressed to Nora Hennies, Neuroscience and Aphasia Research Unit, School of

Psychological Sciences, University of Manchester, Brunswick Street, Manchester M13 9PL, UK. E-mail: n.hennies@uke.de.

DOI:10.1523/JNEUROSCI.3162-15.2016

Copyright $\odot 2016$ Hennies et al.

This is an Open Access article distributed under the terms of the Creative Commons Attribution License Creative Commons Attribution 4.0 International, which permits unrestricted use, distribution and reproduction in any medium provided that the original work is properly attributed. dents (Tse et al., 2007), humans (van Kesteren et al., 2013), and computational modeling (McClelland, 2013) suggests that the relationship between new information and pre-existing knowledge schemas influences this consolidation process. Schemas are coherent frameworks of knowledge and are thought to interact with incoming information at different stages of mnemonic processing, including acquisition, consolidation, and retrieval (Bartlett, 1932; Bransford and Johnson, 1972; Minsky, 1974; Rumelhart, 1980; van Buuren et al., 2014). A striking characteristic of schemas is their beneficial effect on memory (known as the schema effect). Thus, new information that links coherently with a schema is learned more easily than information that does not relate to any existing schema (Bartlett, 1932; Brent, 1969; Johnson, 1970; Bransford and Johnson, 1972; Chase and Simon, 1973; Mandler and Johnson, 1977; van Kesteren et al., 2010a, 2014).

Work in rodents has shown that newly formed memories become independent of the hippocampus more quickly and are retained for longer in the presence of an associative schema (Tse et al., 2007, 2011). During memory consolidation, the hippocam- 
pus is thought to promote a gradual incorporation of newly acquired information into long-term memory by binding, reactivating, and strengthening distributed cortical-cortical connections (Frankland and Bontempi, 2005). While memory consolidation has long been regarded as a slow and gradual process (McClelland et al., 1995), the findings by Tse and colleagues challenge this view. Recent computational simulations based on the complementary learning systems theory (CLS) confirm that the assimilation of schema-consistent information into existing neocortical knowledge structures can proceed rapidly and without interference (McClelland, 2013). Together, these findings suggest that consistency with prior knowledge enables a more efficient incorporation of new information into long-term memory and thereby accelerates hippocampal independence.

A second major influence on memory consolidation is sleep (Diekelmann and Born, 2010). Sleep has been shown to promote various aspects of memory consolidation, including the strengthening and reorganization of memory traces (Frankland and Bontempi, 2005; Rasch and Born, 2013). During sleep, slow oscillations orchestrate the occurrence of sleep spindles and hippocampal sharp wave ripples (SWRs), which have been linked to memory reactivation (Siapas and Wilson, 1998; Sirota et al., 2003; Steriade and Timofeev, 2003; Mölle et al., 2006). The synchronization of these oscillations across the hippocampus and neocortex provides ideal conditions for the hippocampal-neocortical dialogue that underpins memory consolidation (Buzsáki, 1996; Hasselmo, 1999). Furthermore, sleep has been implicated in the process whereby new memories become part of existing knowledge structures (Tamminen et al., 2013). Sleep spindles, in particular, have been shown to play a role in the integration of new information into existing knowledge (Tamminen et al., 2010, 2013). These findings raise the question of how sleep, and specifically sleep spindles, might be related to the accelerated consolidation of memories that fit closely with an existing schema. In the present study, we aimed to explore the role of sleep in memory consolidation in the context of the schema effect. Participants first established a schema and then memorized new information that was either related to the schema [schemarelated (SR) facts] or was completely unrelated [nonschema (NS) facts]. We were interested in sleep-related differences in the consolidation between SR memories and NS memories.

\section{Materials and Methods}

This study consisted of two parts. In the first part participants established a schema by learning information about arthropods (schema A) or cells (schema B) over six separate sessions. In the second part participants memorized SR and NS facts, in two encoding sessions (remote and recent) separated by a $24 \mathrm{~h}$ interval. Sleep during the night between remote and recent encoding sessions was monitored with polysomnography (PSG). Directly after the second (recent) encoding session, we tested memory for the newly learned facts by presenting a learned fact together with a false choice, inside a magnetic resonance imaging (MRI) scanner. A schematic illustration of the procedure is shown in Figure 1. This design allowed us to accomplish the following: (1) compute the difference between memory for recently and remotely learned facts, which served as an approximation of the overnight change in memory; (2) compute the difference between SR and NS memory, which served as a measure for the schema effect; (3) explore how the schema effect changed across time, approximated by the interaction between the schema effect and the recent versus remote difference; and (4) assess whether the overnight change in the schema effect was associated with sleep spindles or slow-wave activity.

\section{Participants}

Twenty-three native British students (mean age: 21.55 years; SD: 2.61 years; six males; randomly assigned to one of the two schemas) partici- pated in this study. All had normal or corrected-to-normal vision, no hearing problems, and no history of neurological, psychiatric, or sleep disorders. Participants were required to have no knowledge beyond that of basic schooling at the primary level in the two schema categories (arthropods and cell biology) and no particular interest in biology, medicine, chemistry, and zoology. Informed consent was obtained from all participants before the study, which was approved by the University of Manchester Research Ethics Committee. Two participants had to be excluded due to technical problems during the encoding and one due to insufficient schema learning, leaving 20 individuals for the analysis.

\section{Stimuli}

Schemas. Each schema comprised information about the category (arthropods or cells) and detailed characteristics of 12 individual category members. A diagrammatic illustration of schemas A and B is shown in Figure 1. The two schemas were highly parallel in structure and contained information at each hierarchical level. For schema A, participants learned general information about arthropods and the two families of arthropods, ants and crabs. Each family was divided into three subfamilies, each containing two individual species. Detailed information (15-25 facts) about anatomy, habitat, food preferences, and behavioral characteristics for each of the 12 species comprised the main part of the schema. Schema B was organized in the same way and contained information about different cells, in particular different cell types and cell organelles. New names were created for all category members of each schema.

Novel, related facts. For each of the 12 category members, six additional facts (SR facts) were created, which were not part of the schema but were used for the encoding of the second part of the study. These facts were new but related to information in the schema. Examples are provided in Table 1. Each fact existed in two, equally likely versions. One version, which was randomly chosen for each participant, was used for the encoding. The other one served as false choice for the recall. This design ensured that participants could not guess the correct answer based on their schema knowledge. The SR facts for schema A served as NS facts for schema B and vice versa. The facts were kept vague to prevent participants from knowing what the NS facts were about. For the same reason, the names of the 12 category members were made up. The facts for schema A and schema B were counterbalanced for the number of words, number of syllables, and numerical values. None of the facts were longer than eight words or 14 syllables so that all facts could easily be read within the presentation time.

\section{Procedure}

Part I: schema-learning. Participants were randomly assigned to one of the two schemas and performed a test on their prior knowledge in that category. This pretest involved pictures and questions about the main category (arthropods or cells) and about the 12 category members. All questions were multiple choice and presented without a time limit. Subjects who achieved a $>20 \%$ performance could not take part in the experiment. The following schema learning involved six sessions, which were spaced on average across $13 \pm 0.7(\mathrm{SE}) \mathrm{d}$ (minimum, $11 \mathrm{~d}$; maximum, $17 \mathrm{~d}$ ). Sessions were $\sim 1.5 \mathrm{~h}$ long, but this could vary as participants were allowed to work through the material at a self-determined pace. The schema information was presented as reading material. A range of different tasks, including free recall, multiple choice questions, open questions, and picture naming tests, were administered in each session to facilitate the learning and to monitor the learning progress. Participants were only allowed to continue with the second part of the experiment (i.e., the encoding phase) when they reached a threshold of $85 \%$ in session six to assure that the schema was fully established. One participant was excluded based on this criterion. The average proportion correct from the remaining participants in the final test session was $0.93 \pm 0.01$ (SE). In addition to schema information, participants also learned the names of the 12 category members of the other schema and completed phonological tasks without knowing their meanings.

Part II: fact encoding. The second phase of the experiment involved two encoding sessions (E1 and E2) and a recall session. The two encoding sessions were separated by $24 \pm 1.5 \mathrm{~h}$ (mean; starting time for E1: 1:36 P.M., SD: 28 min; mean starting time for E2: 12:52 P.M., SD: 18 min). E1 took place on the day following schema-learning session 6 . In each en- 

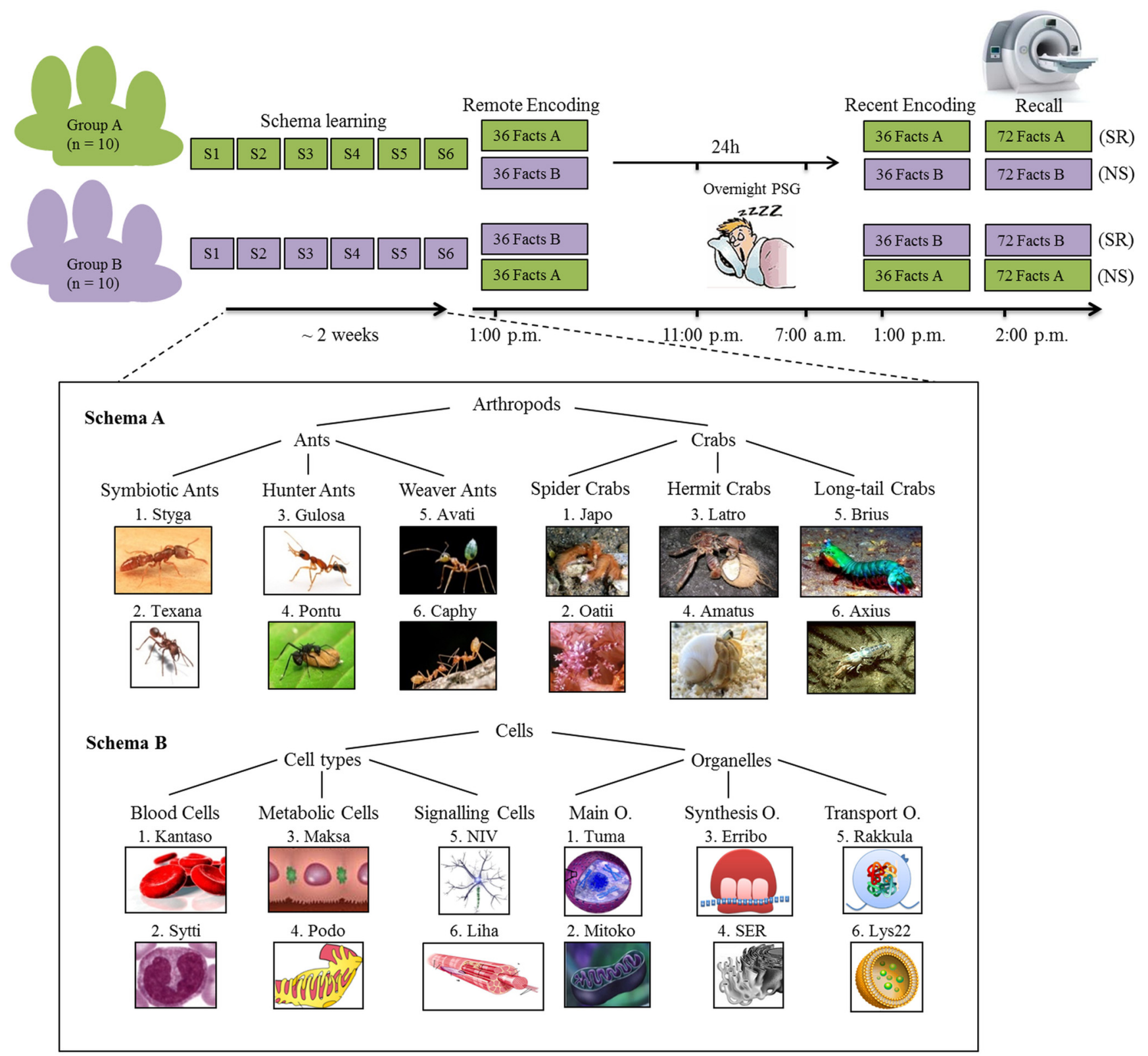

Figure 1. Procedure and illustration of the schema structure. Procedure: participants were randomly assigned to schema A or B. Sessions 1-6, spaced across 2 weeks, comprised the schema learning. In two encoding sessions, spaced by a $24 \mathrm{~h}$ interval, participants learned new SR and NS facts. Sleep was monitored in the night between the two encoding sessions with PSG. The recall took place inside an MRI scanner immediately after the second encoding. Schema structure: schema A comprised general information about arthropods, including the two families ants and crabs and detailed information about the anatomy, habit, food preferences, and characteristics of 12 individual species. Schema B followed the samestructure but included information about different cells types and organelles. The names of the category members of each schema were made up.

\section{Table 1. Examples of the SR facts}

\begin{tabular}{|c|c|c|}
\hline Information in the schema & Fact (version 1) & Fact (version 2) \\
\hline $\begin{array}{l}\text { Oatii is a very colourful crab, } \\
\text { which changes its colour } \\
\text { when the temperature } \\
\text { changes }\end{array}$ & Oatii turns blue in heat & Oatii turns brown in heat \\
\hline Pontu lives for a long time & $\begin{array}{l}\text { Pontu has a lifespan of } 5 \\
\text { years }\end{array}$ & Pontu has a lifespan of 7 years \\
\hline $\begin{array}{l}\text { Gulosa has a hard exoskeleton } \\
\text { due to a high amount of } \\
\text { minerals in its chitin }\end{array}$ & $\begin{array}{l}\text { Gulosa contains potassium } \\
\text { in its shell }\end{array}$ & $\begin{array}{l}\text { Gulosa contains magnesium in } \\
\text { its shell }\end{array}$ \\
\hline
\end{tabular}

coding session, participants were exposed to 36 SR and 36 NS facts. Facts were presented in pseudorandom order (consecutive facts were from different category members), in four presentation rounds. Each fact was presented for $6 \mathrm{~s}$ in the first round and for $4 \mathrm{~s}$ in the remaining three rounds. Each trial started with the presentation of a fact and was followed by a blank screen for 500 ms before the next stimulus appeared. Each participant had a $10 \mathrm{~s}$ break after the presentation of every 18 th facts. After two presentation rounds, participants had a $30 \mathrm{~s}$ break. Each encoding session lasted $\sim 40 \mathrm{~min}$. Participants were instructed to memorize each fact carefully, to focus only at the fact that was presented at the time, and to give each fact equal memorization effort. Participants were also informed about how they would be tested in the recall task. One encoding session involved facts associated with one family of the schema (for example, ants) and one family of the unlearned schema (for example, cells). The other encoding session involved facts associated with the other 
family of the schema (for example, crabs) and the unlearned schema (for example, organelles). This was done to minimize interference between the two encoding sessions. The order was counter-balanced between participants. On the day of E1, participants were invited to sleep overnight from 11:00 P.M. to 7:00 A.M. in a bedroom in the Sleep Research Laboratory at the University of Manchester, where they were monitored with PSG while they slept. The recall took place directly after the second encoding session inside a 3T MRI scanner. All 144 facts were tested in a two-alternative task. Each trial started with the presentation of a fixation cross in the middle of the screen for $500 \mathrm{~ms}$. This was followed by the presentation of a fact together with its false choice for $6000 \mathrm{~ms}$. Participants had to choose the correct answer by pressing the corresponding button on a button box with the right hand within the $6 \mathrm{~s}$ interval. Participants were instructed not to guess, but to press a "Don't know" button in case they were unsure. Seventy-two rest trials lasting $6000 \mathrm{~ms}$ each, in which a fixation cross was presented in the middle of the screen, were included to facilitate estimation of functional MRI (fMRI) baseline activity. Participants conducted five practice trials before they started with the recall task.

\section{Equipment}

This experiment was realized with custom-written scripts using Cogent 2000, developed by the Cogent 2000 team at the Functional Imaging Laboratory and the Institute for Cognitive Neuroscience (University College, London). It was written and executed using Matlab 7.5 running on a PC equipped with a dual-core processor. Responses were recorded using a serial multibutton box attached to a Domino 2 microcontroller from Micromint, with a time resolution of $\sim 1 \mathrm{~ms}$.

\section{PSG data acquisition and analysis}

PSG monitoring was performed using an Embla N7000 sleepmonitoring system (Natus Medical), with $\mathrm{Ag}-\mathrm{AgCl}$ electrodes attached using EC2 electrogel after the scalp was first prepared with NuPrep exfoliating agent (Weaver). Scalp electrodes were attached using the 10-20 system at six standard locations-C3, C4, F3, F4, O1, and $\mathrm{O}_{2}$ - each referenced to the contralateral mastoid (M1 and M2). Left and right electro-oculogram; left, right, and upper electromyogram; and a ground electrode were also attached. All electrodes were verified to have a connection impedance of $<5 \mathrm{k} \Omega$. All signals were digitally sampled at a rate of $200 \mathrm{~Hz}$. Sleep structure was analyzed using RemLogic 1.1 software (Natus Medical). Sleep data were organized into $30 \mathrm{~s}$ epochs and bandpass filtered between 0.3 and $35 \mathrm{~Hz}$ to remove low-frequency drift and high-frequency noise. Sleep data were visually scored independently by two experienced sleep researchers according to the standardized sleep scoring criteria of Rechtschaffen and Kales (1968). The proportion of time spent in each sleep stage and the overall sleep duration were calculated. The spindle analysis involved artifact-rejected, stage 2 nonrapideye movement (NREM) sleep. Raw EEG data were bandpass filtered $(12-15 \mathrm{~Hz})$ using a linear finite impulse response filter. Automated detection (Ferrarelli et al., 2007), which has been widely used in the literature (Tamminen et al., 2013), derived the number of discrete spindle events. Reported results are averaged across channels (C3, C4, F3, F4, O1, and $\mathrm{O} 2$ ). We focused on stage 2 (N2) sleep spindles because prior work shows that $\mathrm{N} 2$ spindles are the most strongly associated with the integration of newly learned information with existing knowledge (Tamminen et al., 2010). Increased connectivity between the neocortex and hippocampus associated with stage 2 spindles (Andrade et al., 2011) and enhanced global synchronization during stage 2 sleep (Genzel et al., 2014) might favor the integration of new information into existing neocortical networks.

\section{Statistical analyses}

A factorial design with factors schema (SR, NS) and delay (recent, remote) was used, which allowed us to compare memory performance across four conditions: SR remote, NS remote, SR recent, and NS recent. Behavioral performance was assessed by calculating the proportion of trials in which the learned fact was correctly identified. Proportions were arcsine-transformed for analyses to better meet the assumption of normality (Judd et al., 2009).
To determine whether physiological aspects of sleep explained the increase of schema effect across time, which was measured by the behavioral interaction score $\mathrm{NS}_{\text {(recent - remote) }}-\mathrm{SR}_{\text {(recent - remote) }}$, we conducted a simultaneous regression analysis with the following variables: total sleep time (TST; in minutes), REM sleep (percentage of TST), stage 1 sleep (percentage of TST), slow-wave sleep (SWS; percentage of TST), and N2 spindle density (number of spindles per minute) as the explanatory variables; and the behavioral interaction score as dependent variable. Multicollinearity was assessed according to the variance inflation factor; because N2 sleep time was correlated with SWS $\left(r_{(19)}=-0.62\right.$, $p<0.01)$ and REM sleep $\left(r_{(19)}=-0.54, p=0.02\right)$, it was not included in the regression model. The remaining predictor variables were found not to be collinear. The association between the schema effect and the N2 spindle density was further explored by a median split analysis, in which participants were divided into two groups based on their spindle density. A $2 \times 2 \times 2$ repeated-measures ANOVA, with factors schema, delay, and spindle group (levels: high spindle group, low spindle group) was used to assess whether the overnight change of the schema effect differed between participants with high spindle densities from those with lower spindle densities. We considered $p<0.05$ as significant and all tests were two tailed. Correlation strengths were compared using the HotellingWilliams test (Sickle, 2003).

\section{fMRI data acquisition and analysis}

fMRI time series data were acquired using a 3T Allegra MR scanner (Siemens) with an eight-channel head coil. Blood oxygen leveldependent signal was recorded using $\mathrm{T} 2{ }^{*}$-weighted fMRI images obtained with a gradient echo-planar sequence. Fifty oblique transaxial slices tilted at $15^{\circ}$ were acquired in an ascending sequence with a voxel size of $3 \times 3 \times 2.8 \mathrm{~mm}^{3}$, including an interslice gap of $40 \%$, matrix size of $64 \times 64$, time repetition of $2960 \mathrm{~ms}$, time echo of $30 \mathrm{~ms}$, and flip angle of $80^{\circ}$. Functional imaging data were processed using the Statistical Parametric Mapping 8 software (SPM8, Wellcome Department of Cognitive Neurology, London, UK; http://www.fil.ion.ucl.ac.uk/spm). Functional images were realigned and corrected for slice acquisition time differences. Images were then transformed into standard stereotaxic space, corresponding to the Montreal Neurological Institute canonical brain. This was accomplished by registering the mean EPI volume to SPM8's EPI template and applying the calculated transform to all image volumes. Finally, a spherical Gaussian smoothing kernel with a full-width at halfmaximum of $8 \mathrm{~mm}$ was applied to the normalized data of each participant. Data analysis was conducted with a two-level, random-effects general linear model (Friston et al., 1994). At the first level, the design matrix contained five regressors. These were the four experimental conditions - SR remote, NS remote, SR recent, and NS recent - and button presses for individual trials modeled as single events with 0 duration. Each regressor was convolved with a canonical hemodynamic response function. Movement parameters were included as six nonconvolved regressors of no interest. Effects of interest were modeled by linear $t$ contrasts at the first level for individual participants. These included onesample $t$ tests for the delay (remote vs recent), schema-relatedness (SR vs NS), and the interaction between delay and schema-relatedness. The contrast images resulting from these first-level analyses were taken forward to second-level one-sample $t$ tests. To investigate neural correlates of our behavioral findings, we investigated brain regions in which spindle density predicted an overnight difference in brain activity between SR and NS memories. Therefore a linear $t$ contrast of the negative interaction $\mathrm{SR}_{\text {(recent }>\text { remote) }}>\mathrm{NS}_{\text {(recent }>\text { remote) }}$ was calculated at the first level. The resulting contrast image was carried forward to a second-level onesample $t$ test and N2 spindle density was included as a covariate. Brain regions that differentiated between conditions were identified using a statistical criterion of $\geq 48$ contiguous voxels at a voxelwise threshold of $p<0.005$. These height and extent thresholds were selected on the basis of a Monte Carlo simulation using 1000 iterations implemented in Matlab, to correspond with an overall false-positive rate of $p<$ 0.05, corrected for multiple comparisons (Slotnick et al., 2003). Based on previous research (Tse et al., 2007; van Kesteren et al., 2012), we focused on our a priori region of interest, the hippocampus. Beta estimates of the resulting clusters were extracted using Marsbar, and 
A

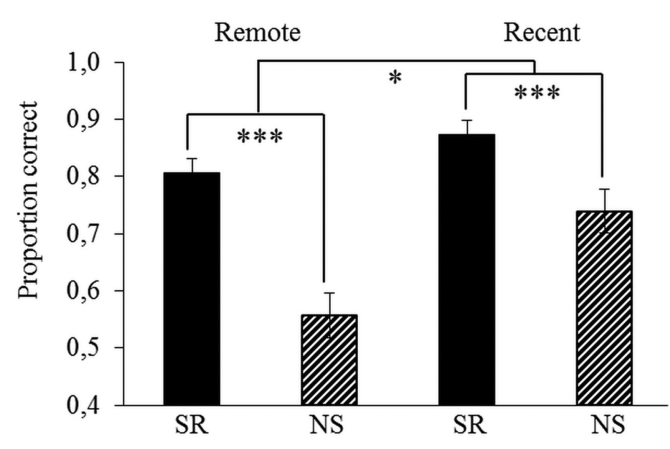

C

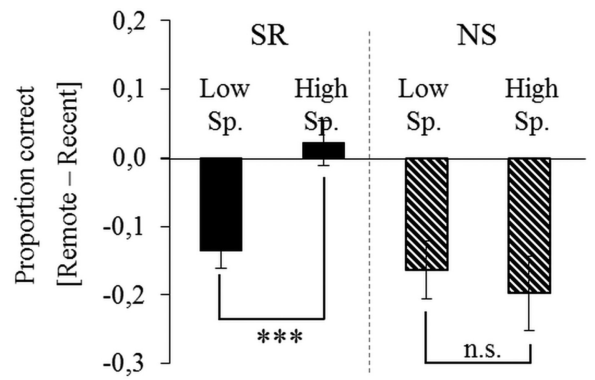

B

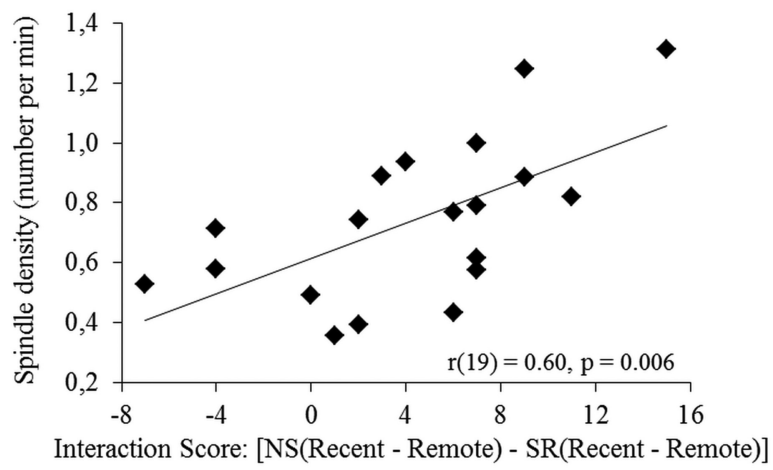

D

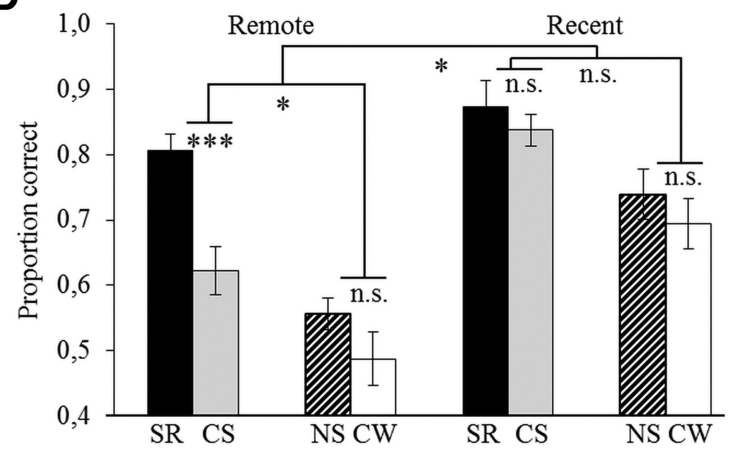

Schema-related (SR) $\square$ Control: non-schema strongly-encoded(CS)

$\square$ Non-schema(NS) $\square$ Control: non-schema weakly-encoded (CW)

Figure 2. Behavioral results. $\boldsymbol{A}$, The proportion of correctly remembered facts. There was a clear schema benefit that was greater for remotely than recently encoded facts. $\boldsymbol{B}$, This overnight increase in the schema effect, which was measured by the interaction score, was predicted by the stage 2 spindle density. C, Results of the median split analysis on the spindle densities of the schema group. For the NS condition there was no difference in the overnight change in memory performance between the low and the high spindle density groups. For the SR condition, the high spindle density group showed no overnight memory change, while the low spindle group showed significant memory decay, indicating that the reduced decay of SR items was associated with participants who had high spindle densities. $D$, Results of the control group compared with the schema group. While the schema group showed significantly less decay of SR memories than NS memories, the control group exhibited an equivalent decay rate for strongly and weakly encoded facts. This was significant in a $2 \times 2 \times 2$ mixed-measures ANOVA. This suggests that the schema manipulation, and not the difference in encoding strength between the SR and NS memories, was driving the increase in the schema effect over time in the schema group. Data are presented as mean \pm SE. Statistical analyses were performed on the arcsine-transformed proportion of correctly remembered facts. Low Sp., Low spindle density group; High Sp., high spindle density group; n.S., not significant. ${ }^{* *} p<0.001,{ }^{* *} p<0.01,{ }^{*} p<0.05$, n.s. $p>0.1$.

correlation and median split analyses were conducted on the $\beta$ estimates averaged across the cluster.

Behavioral control group. Since a behavioral schema effect was present immediately after encoding, the overnight increase in this advantage could potentially be due to differences in encoding strength of the SR and the NS conditions independent of schema-relatedness. To control for this possible confound, we tested an additional experimental group (control group), in which we manipulated encoding strength (weak vs strong), instead of schema-relatedness (SR vs NS). Twenty-four native English students (mean age: 21.9 years; SD: 2.99 years; eight males) were recruited for the control group. The same recruitment criteria as for the schema group were applied. Our aim was to mimic memory performance of the recent condition of the schema group (i.e., high performance in the SR condition and low performance in the NS condition) to then be able to compare how memory performance changed in the remote condition. For this reason, we excluded participants who performed $<3$ SDs from the mean of the SR recently encoded condition of the schema group. Four participants were excluded based on this criterion. Participants completed two encoding sessions (matched in time to the schema study), which were separated by $24 \mathrm{~h}$ and a recall session that took place directly after the second encoding. In the encoding sessions, participants memorized the same 144 facts ( 72 facts per session) that were used in the schema study, but without any prior schema knowledge (i.e., all facts were learned in the NS condition). To create the necessary differences in encoding strength, half of the facts were encoded more than twice as many times ( $9 \times$; strongly encoded facts) as the other half
( $4 \times$; weakly encoded facts). Because participants in the schema group could easily distinguish between SR and NS facts based on their prior knowledge, we used visual cues in the control group, which enabled participants to distinguish between the two groups of facts: strongly encoded facts were presented in purple and weakly encoded facts were presented in yellow. Encoding trials were equivalent and carefully matched to the schema group. Facts were presented in five rounds. In the first round, only the strongly encoded facts were shown. In the other four rounds, the strongly encoded facts were shown twice and the weakly encoded facts once. In the night between the two encoding sessions, participants slept in the sleep laboratory and sleep was monitored with PSG. The PSG acquisition and analysis was equivalent to the original schema group. The recall task was equivalent to the schema group, but without fMRI.

\section{Results}

Behavioral results

Behavioral results are presented in Figure $2 A$. As expected, memory performance was better for SR than for NS facts $\left(F_{(19)}=\right.$ 46.47, $p<0.001$ ), indicating that our schema manipulation was successful. Importantly, we found a significant schema $\times$ delay interaction, with the schema effect being greater for the remote than the recent condition $\left(F_{(19)}=5.24, p=0.034\right)$, and thus suggesting that the schema effect increased across time. 
Table 2. Polysomnography results

\begin{tabular}{lcc}
\hline Parameter & Schema group & Control group \\
\hline TST (in min) & $432 \pm 10.53$ & $459.60 \pm 12.69$ \\
Stage 1 (\% of TST) & $7 \pm 0.94$ & $6.31 \pm 0.71$ \\
Stage 2 (\% of TST) & $53 \pm 1.42$ & $55.15 \pm 1.67$ \\
SWS (\% of TST) & $22 \pm 1.16$ & $19.52 \pm 1.80$ \\
REM (\% of TST) & $17 \pm 0.94$ & $19.02 \pm 0.91$ \\
N2 spindle density & $0.74 \pm 0.06$ & $0.67 \pm 0.30$ \\
\hline
\end{tabular}

Data are presented as mean \pm SE. Stage 1 , stage 2 , SWS, and REM are presented as percentage of TST. Spindle density is the number of spindles per minute of stage 2 (N2) sleep.

\section{Sleep-related results}

Spindle density predicts increase in schema effect

PSG results are presented in Table 2. One participant was excluded from the analysis due to artifacts in the EEG recording. We conducted a multiple-regression analysis to determine whether sleep parameters predicted the increase in the schema effect from the recent to the remote condition. The overall regression model with the explanatory variables TST, percentage of stage $1(\mathrm{~N} 1)$, percentage of REM sleep, percentage of SWS, and $\mathrm{N} 2$ sleep spindle density was significant $\left(F_{(5,13)}=5.63, p=0.006\right)$ and predicted $56.20 \%$ of the variance in the interaction scores (adjusted $R^{2} ; r=0.83$ ). The main factors influencing the overnight change of the schema effect were spindle density $(t=4.11$, $p=0.001)$ and SWS $(t=-3.05, p=0.009)$. No other variable was significant $(|t| \leq 1.57, p \geq 0.14)$. Note that the percentage of SWS was highly correlated with the percentage of N2 sleep. For this reason, N2 sleep was not included in the regression model. Including N2 in the model instead of SWS provided the same results; hence, we cannot differentiate between the contributions of SWS and N2 sleep. Our analyses focus on sleep spindles, which showed a selective effect (for details on the SWS/N2 results, see Association between SWS/N2 and schema effect). Further analyses revealed that spindle density was strongly correlated with the interaction score $\left(r_{(19)}=0.60, p=0.006\right)$, with higher spindle densities predicting greater overnight increases in the schema effect as shown in Figure $2 B$. In other words, participants with higher spindle densities showed less overnight forgetting of the SR compared with the NS items than participants with lower spindle densities. To explore what was driving this correlation, we conducted a median split analysis based on the spindle density (Fig. 2C). We found a significant three-way interaction (delay $X$ schema $\times$ spindle group; $F_{(17)}=22.12, p<0.001$ ). For the NS condition, there was no difference in the overnight change in the proportion of correctly remembered facts between high and low spindle density groups $\left(F_{(17)}=0.69, p=0.42\right)$. For the SR facts, however, this difference was significant $\left(F_{(17)}=20.51, p<\right.$ 0.001 ). The low spindle group showed a significant decrease in the number of correctly remembered items from the recent to the remote condition $\left(t_{(9)}=-7.47, p<0.001\right.$; mean remote: $1.08 \pm$ 0.05 ; mean recent: $1.28 \pm 0.05$ ), while performance in the high spindle group was approximately constant $\left(t_{(8)}=0.59, p=0.57\right.$; mean remote: $1.17 \pm 0.04$; mean recent: $1.14 \pm 0.04)$. Overall, this median split analysis suggests that the overnight increase in the schema effect was driven by the fact that memory for SR items decayed very little in participants with high spindle densities.

To assess whether the correlation between spindle activity and the interaction score was carried by specific sites, we calculated the correlations separately for central (C3, C4), frontal (F3, F4), and occipital $(\mathrm{O} 1, \mathrm{O} 2)$ channels. Central and occipital channels showed significant correlations, frontal channels revealed a trend (central: $r_{(19)}=0.672, p=0.002$; frontal: $r_{(19)}=0.407, p=0.083$; occipital: $\left.r_{(19)}=0.635, p=0.004\right)$. We also inspected the change in the schema effect for slow $(11-13 \mathrm{~Hz})$ and fast $(13-15 \mathrm{~Hz})$ spindles separately. We observed significant and comparable correlations for both spindle types (fast: $r_{(19)}=0.555, p=0.014$; slow: $\left.r_{(19)}=0.544, p=0.016\right)$.

\section{Specificity of the correlation between spindle density and behavioral interaction score}

A correlation between spindle density and the decay of SR memories was marginally significant $\left(r_{(19)}=0.42, p=0.07\right)$. Spindle density did not correlate with the general overnight memory decay $(r=0.02, p=0.95)$, overall memory performance $(r=0.06$, $p=0.83$ ), or memory performance of the first schema learning session $(r=0.01, p=0.98)$, which serves as measure for individual learning potential. No significant correlation (at $\alpha=0.05$ ) was observed between spindle density and memory performance in the control group.

\section{Association between SWS/N2 and schema effect}

The regression analysis revealed that SWS/N2 negatively predicted the interaction score. Thus, the more SWS/N2 a participant had, the smaller the overnight increase in schema effect. Interestingly, this negative association between SWS/N2 and overnight change in the schema effect was driven by a correlation between SWS/N2 and overnight retention of NS memories, but $\operatorname{not} \mathrm{SR}$ memories $\left(\mathrm{NS}_{\text {(recent }- \text { remote) }} * \mathrm{SWS} / \mathrm{N} 2: r_{(20)}=-0.5, p=\right.$ $\left.0.024 ; \mathrm{SR}_{\text {(recent }- \text { remote) }} * \mathrm{SWS} / \mathrm{N} 2: r_{(20)}=-0.07, p=0.76\right)$. Thus more SWS/N2 was associated with better overnight retention of NS memories and hence lower interaction scores. Because percentage of SWS was highly correlated with percentage of N2 sleep, we cannot distinguish between the roles of $\mathrm{N} 2$ and SWS. To assess whether NREM sleep was a better predictor of the schema effect than SWS/N2, we included NREM (including N2 and SWS) into a regression model with the following explanatory variables: TST (in minutes), NREM sleep (percentage of TST), stage 2 spindle density. The overall model was significant $\left(F_{(3,15)}=3,68, p=\right.$ 0.036 ), but only spindle density contributed significantly (spindle density: $t=2.97, p=0.009$; NREM sleep: $t=-0.30, p=0.77$; TST: $t=-0.12, p=0.24)$. We also assessed the correlation between NREM sleep and the behavioral interaction score, which was not significant $\left(r_{(19)}=0.10, p=0.69\right)$. Thus while SWS/N2 explains a considerable amount of the variance in the overnight change of the behavioral schema effect, NREM sleep does not. Further research is needed to clarify the specific relationships between SWS and N2 and the schema benefit on memory.

\section{Control group results}

The behavioral results of the control group are presented in Figure $2 D$. A $2 \times 2$ mixed-measures ANOVA, with factors group (levels: schema group, control group) and encoding strength (levels: strong encoding, weak encoding; note that in the schema group, these levels refer to SR and NS respectively), revealed that as intended memory performance in the recent condition did not differ between the schema and the control group $\left(F_{(1,38)}=0.44\right.$, $p=0.51)$. The same ANOVA was applied to the remote condition. Here we observed a significant difference between groups $\left(F_{(1,38)}=6.46, p=0.015\right)$, and critically a significant interaction $\left(F_{(1,38)}=5.54, p=0.024\right)$. This interaction was driven by lower performance of the control group compared with the schema group on strongly encoded facts $\left(t_{(38)}=3.64, p=0.001\right)$. Performance on weakly encoded facts did not differ between the schema and control group $\left(t_{(38)}=1.07, p=0.29\right)$. These results show that the overnight increase in the schema effect, which we observed in the main experiment, was not driven by encoding strength. Instead, this increase was specific to the schema manipulation, 
A

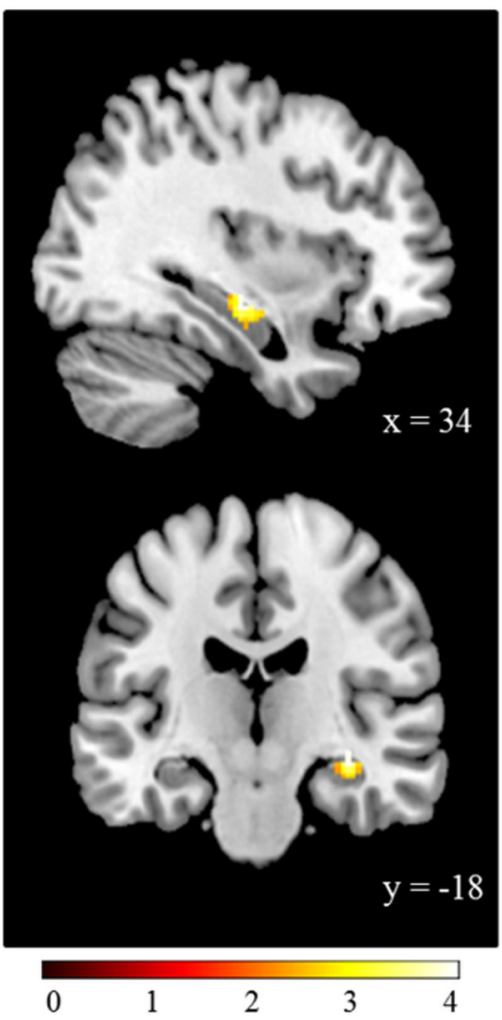

B

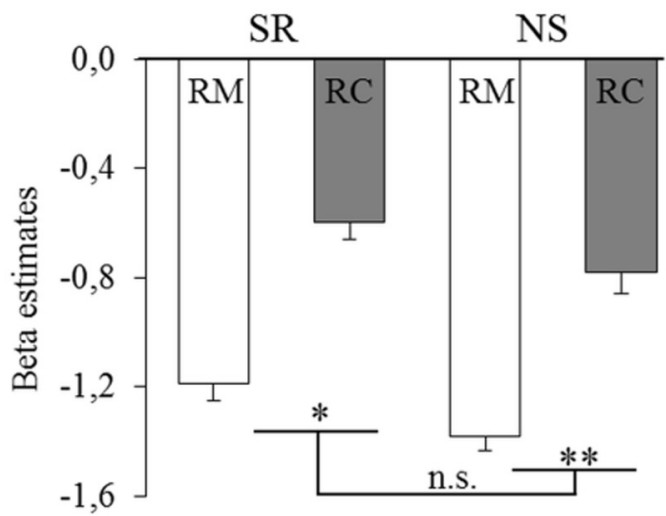

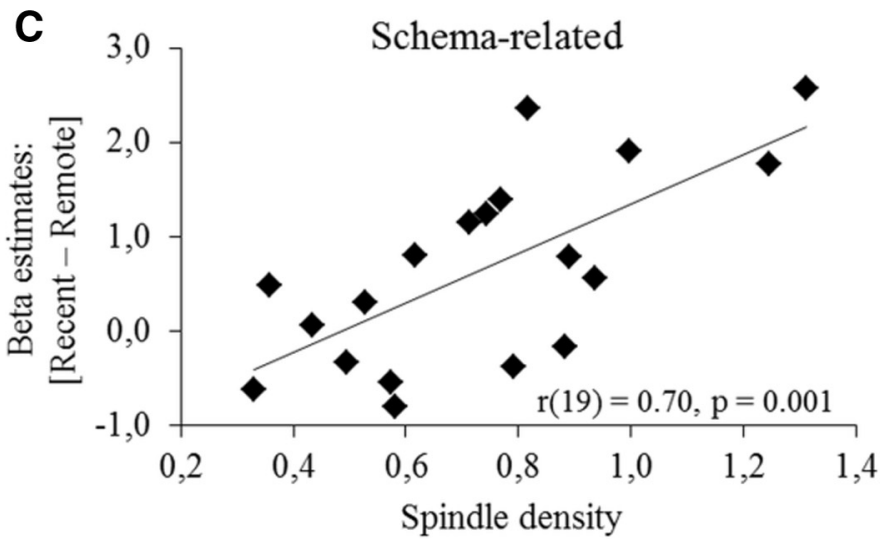

Figure 3. Reduction of activity in the right hippocampus during the recollection of remotely encoded facts compared with recently encoded facts. Hippocampal results are shown at a whole-brain-corrected significance level of $p<0.05$ (voxel-level threshold of $p<0.005$ with a cluster extent threshold of $k=48$ voxels). $\boldsymbol{A}$, Reduction of hippocampal activity during the recollection of remotely encoded facts compared with recently encoded facts. $\boldsymbol{B}$, Average parameter estimates for the cluster shown in $\boldsymbol{A}$ for all four experimental conditions. The overnight change in hippocampal activity did not differ between the SR and NS conditions. C, Sleep spindle density predicted a reduction of activity in the right hippocampus during SR fact recollection. No correlation was observed for NS facts. The color bar indicates $t$ values and activations are superimposed on a standard Montreal Neurological Institute brain. RM, Remote; RC, recent; n.s., not significant. ${ }^{* *} p<0.01,{ }^{*} p<0.05$, n.s. $p>0.1$.

which seems to have led to a protection of SR memories against forgetting. To test the possibility that the association between spindles and overnight change in the schema effect, which we observed for the schema group, was driven by differences in encoding strength rather than the schema effect, we conducted an equivalent regression analysis for the control group (for PSG results, see Table 2). As N2 sleep was strongly correlated with SWS $\left(r_{(20)}=-0.87, p<0.001\right)$, N2 sleep was removed from the regression model, leaving TST, percentage REM sleep, percentage stage 1 sleep, percentage SWS, and stage 2 spindle density as explanatory variables. Tolerance statistics indicated no problems regarding multicollinearity of the remaining explanatory variables. The regression model was not significant $\left(F_{(5,14)}=0.83\right.$, $p=0.55)$, and none of the variables had a significant contribution $(t \leq 1.7, p \geq 0.1)$. We also explored whether stage 2 sleep spindle densities correlated with the behavioral interaction score. We found that the correlation was not significant $\left(r_{(20)}=-0.06\right.$, $p=0.79)$. Moreover, the correlations between spindle densities and behavioral interaction scores were significantly stronger in the schema compared with the control group $\left(z_{(38)}=2.22, p=\right.$ $0.03)$. This suggests that the association between spindles and the overnight change of the schema effect was specific to the schema manipulation.

\section{Neuroimaging results}

Brain activity associated with time-dependent memory change Functionally, we first assessed differences in hippocampal activity during the recollection of recently and remotely encoded facts

\section{Table 3. Significant activation clusters for the overnight change}

\begin{tabular}{|c|c|c|c|c|}
\hline Region of activation & $\begin{array}{l}\text { Cluster extent } \\
\text { (voxels) }\end{array}$ & $\begin{array}{l}\text { Maximum } \\
z \text { value }\end{array}$ & $p$ value & $\begin{array}{l}\text { Peak Montreal } \\
\text { Neurological Institute } \\
\text { coordinate }\end{array}$ \\
\hline \multicolumn{5}{|l|}{ Recent $>$ remote } \\
\hline Precuneus (R/L) & 29,764 & 5.74 & $<0.001$ & $-2-70 \quad 38$ \\
\hline Precentral gyrus (L) & 418 & 4.33 & $<0.001$ & $\begin{array}{lll}-44 & 2 & 18\end{array}$ \\
\hline Lentiform nucleus (R) & 661 & 4.00 & $<0.001$ & $24-10-4$ \\
\hline Middle frontal gyrus (L) & 405 & 4.00 & $<0.001$ & $\begin{array}{lll}-36 & 40 & 32\end{array}$ \\
\hline Medial frontal gyrus (R) & 347 & 3.99 & $<0.001$ & $\begin{array}{lll}18 & 54 & 10\end{array}$ \\
\hline Hippocampus (R) & 93 & 3.81 & $<0.001$ & $34-18-12$ \\
\hline Parahippocampus (R) & 53 & 3.77 & $<0.001$ & $26-22-30$ \\
\hline Medial frontal gyrus (L) & 479 & 3.63 & $<0.001$ & $-12 \quad 54$ \\
\hline Middle temporal gyrus (R) & 57 & 3.50 & $<0.001$ & $2-14$ \\
\hline Middle frontal gyrus (R) & 219 & 3.44 & $<0.001$ & $\begin{array}{lll}38 & 38 & 30\end{array}$ \\
\hline Midbrain (R) & 132 & 3.41 & $<0.001$ & $6-26-4$ \\
\hline Superior frontal gyrus $(\mathrm{L})$ & 58 & 3.36 & 0.001 & $\begin{array}{lll}-12 & 56 & 24\end{array}$ \\
\hline Insula (L) & 169 & 3.17 & 0.001 & $\begin{array}{lll}-46 & 4 & 2\end{array}$ \\
\hline Superior temporal gyrus $(\mathrm{L})$ & 58 & 3.14 & 0.001 & $-54-18$ \\
\hline \multicolumn{5}{|l|}{ Remote $>$ recent } \\
\hline Inferior frontal gyrus (L) & 51 & 3.58 & $<0.001$ & $\begin{array}{lll}-34 & 22 & -8\end{array}$ \\
\hline
\end{tabular}

Voxelwise threshold of $p=0.005$ and extent threshold of $k>48$ voxels, which corresponds with an overall false-positive rate of $<5 \%$, corrected for multiple comparisons (Slotnick et al., 2003). L, left; R, right.

(recent $>$ remote). We observed a cluster in the right hippocampus, shown in Figure $3 A$ (peak: $[34-18-12$ ]; cluster size: 93 voxels; Table 3 ). Within this hippocampal cluster, $\beta$ estimates revealed that the overnight change in activity did not differ be- 
Table 4. Significant activation clusters for the schema effect

\begin{tabular}{|c|c|c|c|c|}
\hline Region of activation & $\begin{array}{l}\text { Cluster extent } \\
\text { (voxels) }\end{array}$ & $\begin{array}{l}\text { Maximum } \\
z \text { value }\end{array}$ & $p$ value & $\begin{array}{l}\text { Peak Montreal } \\
\text { Neurological Institute } \\
\text { coordinate }\end{array}$ \\
\hline \multicolumn{5}{|l|}{$S R>N S$} \\
\hline BA 40 (L) & 341 & 4.14 & $<0.001$ & $-58-32 \quad 30$ \\
\hline Anterior cingulate (BA 32) & 184 & 4.08 & $<0.001$ & $\begin{array}{lll}4 & 32 & -8\end{array}$ \\
\hline Cerebellum anterior lobe (R) & 505 & 4.07 & $<0.001$ & $20-46-18$ \\
\hline Cerebellum (L) & 264 & 4.07 & $<0.001$ & $-14-64-22$ \\
\hline Superior temporal gyrus (R) & 678 & 4.01 & $<0.001$ & $64-24 \quad 16$ \\
\hline BA 44 (R) & 49 & 3.97 & $<0.001$ & $\begin{array}{lll}56 & 10 & 12\end{array}$ \\
\hline Superior temporal gyrus (L) & 876 & 3.80 & $<0.001$ & $\begin{array}{lll}-48 & 0 & 6\end{array}$ \\
\hline Parahippocampus (L) & 179 & 3.75 & $<0.001$ & $-24-42-6$ \\
\hline $\begin{array}{l}\text { Middle temporal gyrus, } \\
\text { BA } 39 \text { (R) }\end{array}$ & 298 & 3.61 & $<0.001$ & $50-72 \quad 30$ \\
\hline Posterior cingulate (R) & 476 & 3.56 & $<0.001$ & $12-54 \quad 22$ \\
\hline Parahippocampus (L) & 81 & 3.54 & $<0.001$ & $-28-26-28$ \\
\hline Middle frontal gyrus (L) & 57 & 3.50 & $<0.001$ & $-32 \quad 38-14$ \\
\hline Putamen (R) & 62 & 3.46 & $<0.001$ & 20 \\
\hline Putamen (L) & 50 & 3.22 & $<0.001$ & 84 \\
\hline Cerebellar tonsil (R) & 51 & 3.00 & 0.001 & $4-52-44$ \\
\hline Middle temporal gyrus (R) & 50 & 2.88 & 0.002 & $-62-54$ \\
\hline \multicolumn{5}{|l|}{$N S>S R$} \\
\hline Cingulate gyrus (L) & 544 & 4.60 & $<0.001$ & $\begin{array}{lll}-8 & 22 & 42\end{array}$ \\
\hline Middle frontal gyrus (L) & 225 & 3.71 & $<0.001$ & $\begin{array}{lll}-26 & 50 & 12\end{array}$ \\
\hline Superior frontal gyrus (R) & 50 & 3.32 & 0.001 & $18 \quad 48-10$ \\
\hline Pons & 52 & 3.18 & 0.001 & $2-38-28$ \\
\hline $\begin{array}{l}\text { Middle occipital gyrus, } \\
\text { BA } 18 \text { (L) }\end{array}$ & 57 & 3.18 & 0.001 & $-36-88$ \\
\hline
\end{tabular}

Voxelwise threshold of $p=0.005$ and extent threshold of $k>48$ voxels, which corresponds with an overall false-positive rate of $<5 \%$, corrected for multiple comparisons (Slotnick et al., 2003). L, Left; R, right; BA, Brodmann area.

tween SR and NS memories $\left(t_{(19)}=0.016, p=0.99\right.$; Fig. $\left.3 B\right)$. As the behavioral results showed an association between sleep spindles and the retention of SR memories, we examined whether spindle density was also associated with the observed decrease in hippocampal engagement across consolidation. We therefore examined correlations between spindle density and the parameter estimates for the overnight change in activity within the identified hippocampal cluster separately for the SR and the NS condition. Interestingly sleep spindles predicted an overnight change for the SR condition (Fig. $3 C ; r_{(19)}=0.692, p=0.001$ ), but not for the NS condition $\left(r_{(19)}=0.321, p=0.180\right)$, at a Bonferronicorrected $\alpha$-level of 0.025 , suggesting that spindles may be specifically associated with the consolidation of SR memories.

\section{Brain activity associated with schema-relatedness}

Differences in activity between SR and NS memory retrieval are presented in Table 4 . This contrast did not reveal any significant activation within the hippocampus. Interestingly, we found significant activation in the anterior cingulate (BA 32), a region that has been observed previously during memory retrieval in relation to the schema effect (van Kesteren et al., 2010b; Brod et al., 2015). However, activation in this region only revealed a marginally significant modulation by time $\left(t_{(19)}=1.91, p=0.07\right)$, with a greater difference between SR and NS memories for the recent than the remote condition, and did not correlate with sleeprelated measures (SWS: $r_{(20)}=0.11, p=0.66$; spindle density: $\left.r_{(19)}=-0.03, p=0.89\right)$.

Brain activity associated with the interaction between schemarelatedness and time-dependent memory change

To assess brain regions that showed differences in the overnight activation change between the SR and the NS condition, we examined the interaction between the factors schema and delay.
Table 5. Significant activation clusters for the interaction contrast $\mathrm{SR}_{\text {(recent }>\text { remote) }}>\mathrm{NS} \mathrm{S}_{\text {(recent }>\text { remote), }}$ which describes the differences in the overnight activation change between the SR and the NS condition

\begin{tabular}{|c|c|c|c|c|}
\hline Region of activation & $\begin{array}{l}\text { Cluster extent } \\
\text { (voxels) }\end{array}$ & $\begin{array}{l}\text { Maximum } \\
z \text { value }\end{array}$ & $p$ value & $\begin{array}{l}\text { Peak Montreal Neurological } \\
\text { Institute coordinate }\end{array}$ \\
\hline Precuneus (L/R) & 690 & 4.65 & $<0.001$ & $-4-68 \quad 44$ \\
\hline Superior frontal gyrus (L) & 278 & 3.70 & $<0.001$ & $-14 \quad 38 \quad 22$ \\
\hline Cingulate gyrus (R) & 246 & 3.75 & $<0.001$ & 846 \\
\hline Medial frontal gyrus (L) & 56 & 3.73 & $<0.001$ & $-12-18 \quad 52$ \\
\hline Middle temporal gyrus (R) & 313 & 3.70 & $<0.001$ & $52-18-6$ \\
\hline Supramarginal gyrus (R) & & 3.68 & $<0.001$ & $50-36 \quad 30$ \\
\hline Precentral gyrus (L) & 76 & 3.61 & $<0.001$ & $40-18 \quad 52$ \\
\hline Middle frontal gyrus (L) & 146 & 3.39 & $<0.001$ & $\begin{array}{lll}30 & 50 & 22\end{array}$ \\
\hline Inferior parietal (L) & 50 & 3.01 & 0.001 & $-46-34 \quad 26$ \\
\hline Cerebellum (R) & 82 & 3.89 & $<0.001$ & $18-64-38$ \\
\hline Thalamus (L) & 64 & 3.50 & $<0.001$ & $-10-32 \quad 12$ \\
\hline
\end{tabular}

Voxelwise threshold of $p=0.005$ and extent threshold of $k>48$ voxels, which corresponds with an overall false-positive rate of $<5 \%$, corrected for multiple comparisons (Slotnick et al., 2003). No significant activation was

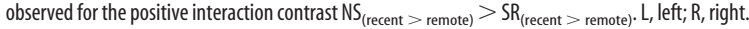

Based on the results by Tse et al. (2007), we expected greater overnight decrease in hippocampal activity for the SR than the NS condition. We were therefore especially interested in the negative interaction contrast $\mathrm{SR}_{\text {(recent }>\text { remote) }}>\mathrm{NS}_{\text {(recent }>\text { remote) }}$, which identified brain regions that showed greater overnight change in activity for the SR than the NS condition. However, no significant effects were observed within our regions of interest (Table 5).

\section{Sleep-related brain activation}

Behaviorally, sleep spindles predicted an overnight increase in the schema effect, driven by less decay of SR memories compared with NS memories. These results are in line with the idea that sleep spindles play a role in the integration of new, hippocampusdependent information with pre-existing neocortical knowledge structures (Tamminen et al., 2013), which in turn may result in a schema-dependent acceleration of hippocampal independence (Tse et al., 2007). To assess whether spindles were associated with a greater overnight decrease in hippocampus dependence for SR than NS memories, we performed a whole-brain analysis of the negative interaction contrast $\mathrm{SR}_{\text {(recent }>\text { remote) }}>\mathrm{NS}_{\text {(recent }>\text { remote) }}$ with stage 2 spindle density included as a covariate. This covariate identified brain regions where spindle density predicted the interaction contrast, i.e., regions where higher spindle densities predicted a greater overnight change in activity for the SR than the NS condition. A right posterior hippocampal cluster, shown in Figure $4 A$ and Table 6, responded strongly to this comparison. In this cluster, higher spindle densities were associated with greater overnight decrease in activity for the SR condition than the NS condition, while lower spindle densities predicted the opposite. Significant activation was also observed in the left posterior hippocampus. However, this cluster was not clearly located in the hippocampus but fell largely in the ventricle. To determine whether the relationship between spindles and the result of our schema $\times$ consolidation interaction contrast was driven by one of the two conditions (SR or NS), we examined correlations between spindle density and the parameter estimates for the recent $>$ remote contrast, separately for the SR and the NS condition (Fig. 4C,D). For SR facts, spindle density was strongly associated with the overnight change in hippocampal activity $\left(r_{(19)}=-0.715, p=0.001\right)$. Thus participants with higher spindle densities showed a greater overnight decrease in hippocampal involvement than participants with lower spindle densities. For NS facts, there was no such association $\left(r_{(19)}=0.204, p=0.402\right)$. These correlations differed marginally in strength $\left(t_{(16)}=2.01\right.$, 
A
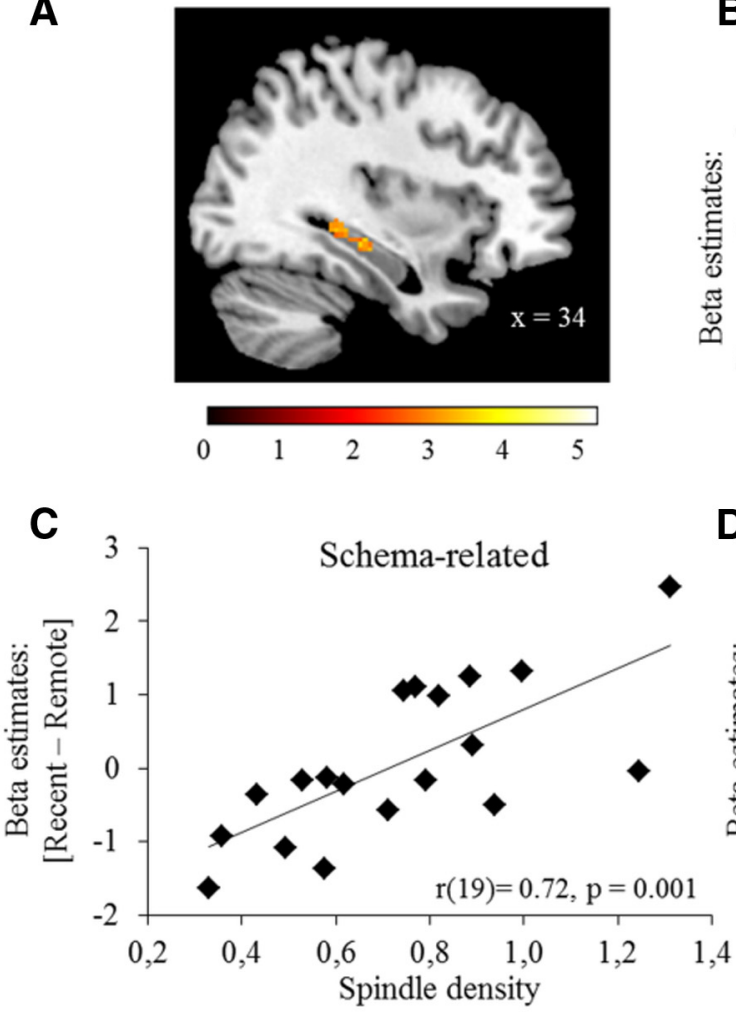
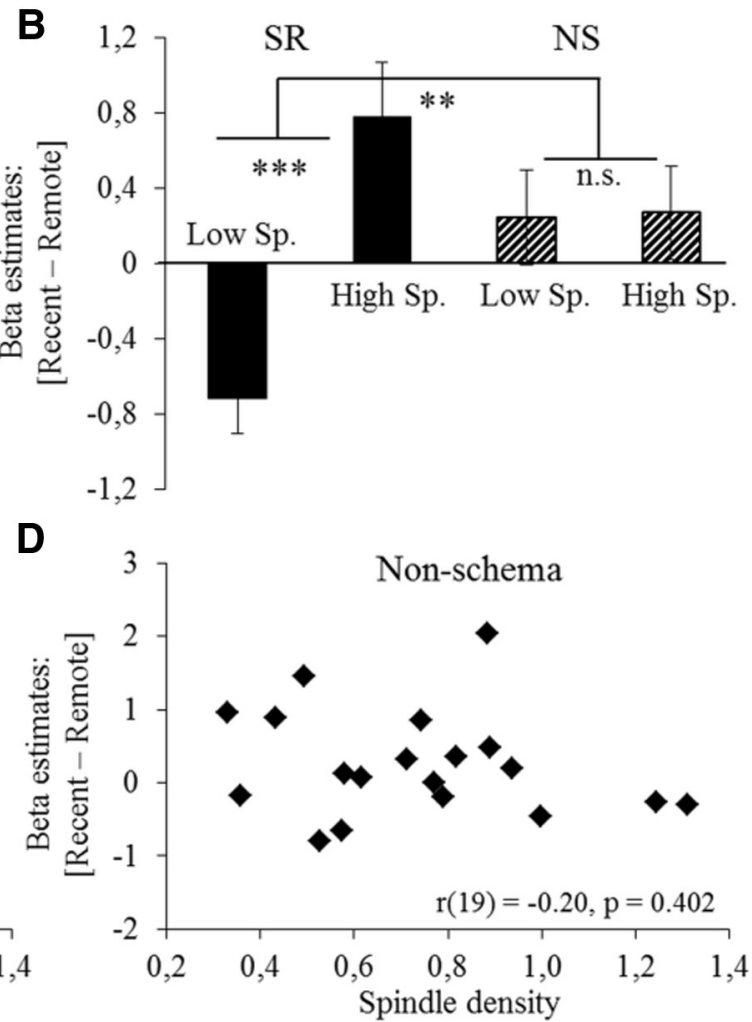

Figure 4. Spindles predict the overnight change in hippocampal activity differentially for SR and NS memories. $A$, Increased spindle density predicted a reduction of activity in the right hippocampus for the interaction contrast $\mathrm{SR}_{\text {(recent }>\text { remote) }}>\mathrm{NS}_{\text {(recent }>\text { remote) }}$. Results are shown at a whole-brain-corrected significance level of $p<0.05$ (voxel-level threshold of $p<0.005$ with a cluster extent threshold of $k=48$ voxels). $\boldsymbol{B}$, Results of a median split analysis on the parameter estimates of the cluster shown in $\boldsymbol{A}$, based on the spindle density. The overnight change in hippocampal activity differed between low and high spindle density groups only for the SR condition. $C$, Spindle densities were highly correlated with the overnight change in hippocampal activity of the SR condition. $\boldsymbol{D}$, No association between spindles and a change in hippocampal activity across consolidation was present for the NS condition. The color bar indicates $t$ values and activations are superimposed on a standard Montreal Neurological Institute brain. Low Sp., Low spindle density group; High Sp., high spindle density group; $n$.S., not significant. ${ }^{* * *} p<0.001,{ }^{* *} p<0.01$, n.S. $p>0.1$.

Table 6. Significant activation clusters for the interaction contrast modulated by the stage 2 spindle density

\begin{tabular}{|c|c|c|c|c|}
\hline Region of activation & $\begin{array}{l}\text { Cluster } \\
\text { extent } \\
\text { (voxels) }\end{array}$ & $\begin{array}{l}\text { Maximum } \\
\text { z value }\end{array}$ & $p$ value & $\begin{array}{l}\text { Peak Montreal } \\
\text { Neurological Institut } \\
\text { coordinate }\end{array}$ \\
\hline \multicolumn{5}{|c|}{ 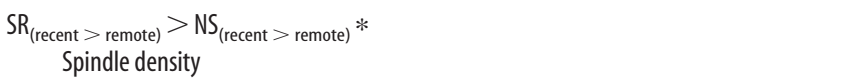 } \\
\hline Hippocampus (R) & 96 & 3.19 & $<0.001$ & $34-26-10$ \\
\hline Ventricle/hippocampus (L) & 170 & 4.37 & $<0.001$ & $-26-42$ \\
\hline Frontal inferior operculum (L) & 79 & 4.05 & $<0.001$ & $\begin{array}{lll}-50 & 12 & 10\end{array}$ \\
\hline \multicolumn{5}{|c|}{$\begin{array}{l}\mathrm{NS}_{\text {(recent }}>\text { remote) } \\
\quad \text { Spindle density }\end{array}$} \\
\hline Cingulate (L) & 48 & 4.07 & $<0.001$ & $\begin{array}{lll}-18 & -8 & 42\end{array}$ \\
\hline Cingulate (R) & 54 & 3.24 & 0.001 & $\begin{array}{lll}14 & 12 & 28\end{array}$ \\
\hline Cerebellum (L) & 59 & 3.55 & $<0.001$ & $-24-42-36$ \\
\hline Precentral gyrus (R) & 63 & 3.44 & $<0.001$ & $10-34 \quad 66$ \\
\hline Middle temporal gyrus (L) & 83 & 3.07 & 0.001 & $44-62 \quad 12$ \\
\hline
\end{tabular}

Voxelwise threshold of $p=0.005$ and extent threshold of $k>48$ voxels, which corresponds with an overall false-positive rate of $<5 \%$, corrected for multiple comparisons (Slotnick et al., 2003). L, Left; $R$, right.

$p=0.06)$. In parallel to our behavioral analysis, a median split, in which participants were divided based on their spindle densities into either a low or a high spindle density group, was conducted on the parameter estimates of this hippocampal cluster (Fig. 4B). While there was a clear difference in the overnight change in hippocampal activity between the low and the high spindle density groups for the SR condition $\left(t_{(17)}=4.35, p<0.001\right)$, no difference was observed for the NS condition $\left(t_{(17)}=0.07, p=\right.$ $0.94)$.

\section{Sleep, brain activation, and behavior}

Finally, we tested for a relationship between our behavioral and functional results by extracting the parameter estimates of the peak coordinate from the right hippocampal cluster, which responded to the schema $\times$ delay $\times$ spindles interaction, and by testing for a correlation with the behavioral interaction score. This revealed a strong predictive relationship between behavioral facilitation and the spindle-mediated decrease in hippocampal involvement $\left(r_{(19)}=-0.57, p=0.009\right)$. Thus, participants with higher spindle densities who showed less forgetting of SR than NS facts also showed a greater overnight change in hippocampal activity for SR than NS facts. Overall, these results suggest that the rate of stage 2 spindles marks the difference in the consolidation between SR and NS memories, which is reflected in a beneficial effect on memory and decreased hippocampal involvement across time for SR memories.

In summary, hippocampal disengagement across time did not differ between SR and NS memories unless spindle density was taken into account. In line with our behavioral results, hippocampal decay for SR memories was predicted by spindle density. Thus, participants with high spindle densities showed greater hippocampal disengagement than participants with low spindle densities. This was not the case for NS memories. The association between spindle density and hippocampal disengagement was also significant in the interaction contrast when spindle 
density was added as a covariate. Thus, participants with high spindle densities showed greater hippocampal disengagement for SR than NS memories and also showed a greater behavioral schema benefit than participants with low spindle densities.

\section{Discussion}

This study investigated the benefit of prior knowledge on memory retention across $24 \mathrm{~h}$ and explored whether this relates to sleep. We found an overnight increase in schema effect, driven by protection of SR memories against decay. Importantly, this schema-dependent memory stabilization was predicted by spindle density. Higher spindle densities were also associated with reduced hippocampal engagement across time, specifically for SR memories. These results suggest that sleep spindle density predicts schema-dependent consolidation, as reflected in superior memory and accelerated hippocampal disengagement.

Only recently has research started to investigate neural mechanisms behind the beneficial effect of schemas on memory. Rodent work and computational explorations suggest that schemas act as catalysts for memory consolidation by accelerating the shift toward neocortical rather than hippocampal regions (Tse et al., 2007, 2011; McClelland, 2013). Using a flavor-place association task in rodents, Tse et al. (2007) demonstrated that consolidation of new information into schemas occurred rapidly such that, after $<48 \mathrm{~h}$, hippocampal integrity was unnecessary for memory retrieval. Computational simulations extending those reported by McClelland et al. (1995) demonstrated that new information consistent with existing neocortical knowledge structures can indeed be learned rapidly and without interference (McClelland, 2013). Thus, in line with our results, information that can be easily incorporated into prior knowledge schemas is remembered better and for longer (Tse et al., 2007). But why do consolidated (schema-related) memories decay less rapidly? One possibility is that memories that have not yet consolidated are more vulnerable to retroactive interference from other mental processes than memories that are consolidated and integrated in the neocortex (Wixted, 2004). After all, sleep has been shown to protect memories from future interference (Ellenbogen et al., 2006) and even to rescue memories damaged by interference ( $\mathrm{McDevitt}$ et al., 2015).

Against expectations based on the results by Tse et al. (2007), but in line with previous human studies (van Kesteren et al., 2010b; van Buuren et al., 2014; Brod et al., 2015), we did not observe reduced hippocampal activation for the retrieval of SR than NS memories. Importantly, however, participants with high spindle densities showed greater hippocampal disengagement for SR than NS memories, while participants with low spindle densities did not. In line with our behavioral finding, this was driven by a strong association between spindle density and overnight hippocampal disengagement for SR memories. Thus, higher spindle density predicts reduced hippocampal dependence, possibly indicating more efficient neocortical consolidation of schema-related memories. This is consistent with McClelland's CLS model (McClelland, 2013), in which there is a greater shift in the division of labor toward the neocortex and away from the hippocampus for new SR information. These human findings build on rodent results (Tse et al., 2007, 2011) by demonstrating an association between sleep spindles and augmented overnight consolidation of SR memories.

Since sleep was recorded during only one night, it remains unclear whether this relationship is driven by trait-like or statelike spindle aspects (De Gennaro and Ferrara, 2003). Spindle activity shows large interindividual differences, but has a remark- able trait-like stability within an individual across nights (Kerkhof, 1991; Finelli et al., 2001; De Gennaro et al., 2005; Buckelmüller et al., 2006; Piantoni et al., 2013). Such trait-like spindle measures have been related to "general learning aptitude" (Gais et al., 2002; Schabus et al., 2006, 2008; Lustenberger et al., 2015) and intellectual ability (Bódizs et al., 2005; Fogel et al., 2007; Fogel and Smith, 2011). Trait-like characteristics of spindles may even relate to the individual traits of functional anatomy, especially of the thalamocortical system (De Gennaro and Ferrara, 2003; De Gennaro et al., 2005; Piantoni et al., 2013), with high spindle density representing efficient thalamocortical system and cortical-subcortical connectivity (Schabus et al., 2006; Fogel and Smith, 2011; Piantoni et al., 2013). In this sense, spindle density may mark more efficient neocortical processing, which in turn may relate to more efficient assimilation of memories into existing neocortical networks. In addition to trait-like characteristics, spindles can vary from one night to another within the same individual. Such state-like variation is thought to play a role in sleep-dependent memory consolidation by shaping neuronal networks after learning (De Gennaro and Ferrara, 2003). Learning-related increases in spindles have been reported in a broad range of studies (Gais et al., 2002; Schabus et al., 2004; Schmidt et al., 2006; Fogel and Smith, 2011; Tamminen et al., 2013; Lustenberger et al., 2015). Further support for causal involvement of spindles in memory consolidation comes from neurophysiological studies (Siapas and Wilson, 1998; Sirota et al., 2003), a study in humans linking memory replay to spindle activity (Bergmann et al., 2012), and a pharmacological study by Mednick et al. (2013). Importantly, spindle activity has also been implicated in the integration of new information with existing knowledge. Tamminen and colleagues (Tamminen et al., 2010) demonstrated that participants with higher spindle densities showed larger overnight increases in lexical competition, reflecting enhanced integration, which is in line with the superior retention of SR memories that we observed here. What role could spindles play in the assimilation of information into neural networks? Spindles could potentially trigger neocortical plasticity (Timofeev et al., 2002; Rosanova and Ulrich, 2005). For example, Rosanova and Ulrich (2005) demonstrated that a natural firing pattern recorded in an anesthetized cat during sleep spindles induced long-term potentiation at excitatory connections in pyramidal cells in vitro. These epochs of heightened plasticity, induced by spindles, tend to occur in close temporal correlation with hippocampal SWR (Siapas and Wilson, 1998; Sirota et al., 2003; Clemens et al., 2007). SWRs are linked to the reactivation of memories and are thought to play a crucial role in memory consolidation (Buzsáki, 1989; Wilson and McNaughton, 1994; Lee and Wilson, 2002; Girardeau et al., 2009; Ramadan et al., 2009; Ego-Stengel and Wilson, 2010). The coupling of these network events effectively links neocortical and hippocampal cell assemblies (Sirota et al., 2003) and seems to provide ideal conditions for a coordinated hippocampal-neocortical information exchange (Siapas and Wilson, 1998; Sirota et al., 2003). These proposed mechanisms for spindle activity could underpin the integration of newly encoded hippocampal-dependent memories into existing neocortical networks. If new information is consistent with existing neocortical representations, it is assimilated more efficiently (McClelland, 2013) and therefore might benefit more from the proposed integrative function of spindles, which is in keeping with our current findings. Participants who showed an increase in the schema effect across consolidation (i.e., had better retention of SR than NS memories), assimilated SR memories more efficiently into the neocortex, as indexed by higher spindle 
densities and decreased hippocampal engagement. Thus spindlecorrelated neocortical consolidation of new information is accompanied by a concomitant reduction in hippocampal support. Notably, however, our study has only limited ability to reveal the association between sleep spindle density and schema benefit to memory. Future research should determine whether schemadependent performance changes after sleep reflect sleep-related consolidation processes, mirror a general learning trait, or relate to both state and trait influences.

So far only one other study (Durrant et al., 2015) has shown a relationship between sleep and the schema benefit on memory. Here, participants learned short new melodies that either conformed to the schema of Western tonal music, or did not, and were thus probably less pleasant (Droit-Volet et al., 2013). Memory for schema-congruent but not schema-incongruent melodies improved overnight and this improvement was predicted by REM sleep (Durrant et al., 2015). The apparent REM dependency of musical schemas contrasts markedly with the link we observe between the declarative schema and sleep spindles. This difference may relate to the differences between the schemas in question, as REM sleep is associated with both procedural memory and emotion (Nishida and Walker, 2007; van der Helm and Walker, 2011; Spoormaker et al., 2012), while NREM sleep is associated with declarative memory (Ackermann and Rasch, 2014). Together these findings support the idea that prior knowledge affects sleep-dependent consolidation processes, but further research is needed to determine whether the observed relationships reflect causal involvement of sleep.

The current study is limited by both correlative nature and small sample size. Although spindle activity has been associated with both state and trait measures of cognitive variables (Fogel and Smith, 2011), conflicting results also exist (Ujma et al., 2014; Ackermann et al., 2015). Neither the relationship between spindle activity and memory consolidation (Ackermann et al., 2015) nor between spindle activity and intelligence (Ujma et al., 2014) are invariantly observed. Differences in the spindle parameters assessed complicate the picture and small sample sizes, although typical of sleep studies, increase the probability of overestimating the real association strength (Ackermann et al., 2015). Hence we must interpret the results cautiously. Further research should confirm the observed association and investigate potential causal relationships.

In summary, our results suggest a role for sleep spindles in schema-dependent memory consolidation. We found that the rate of sleep spindles predicts memory retention and hippocampal disengagement specifically for memories, which relate to prior knowledge. This is consistent with the suggestion that sleep spindles predict hippocampal-to-neocortical consolidation, and extends this idea to show that spindles may mediate interactions between existing knowledge and new learning.

\section{References}

Ackermann S, Rasch B (2014) Differential effects of non-REM and REM sleep on memory consolidation? Curr Neurol Neurosci Rep 14:430. CrossRef Medline

Ackermann S, Hartmann F, Papassotiropoulos A, de Quervain DJ, Rasch B (2015) No associations between interindividual differences in sleep parameters and episodic memory consolidation. Sleep 38:951-959. CrossRef Medline

Andrade KC, Spoormaker VI, Dresler M, Wehrle R, Holsboer F, Sämann PG, Czisch M (2011) Sleep spindles and hippocampal functional connectivity in human NREM sleep. J Neurosci 31:10331-10339. CrossRef Medline

Bartlett FC (1932) Remembering: a study in experimental and social psychology. New York: Cambridge UP.

Bergmann TO, Mölle M, Diedrichs J, Born J, Siebner HR (2012) Sleep spindle-related reactivation of category-specific cortical regions after learning face-scene associations. Neuroimage 59:2733-2742. CrossRef Medline

Bódizs R, Kis T, Lázár AS, Havrán L, Rigó P, Clemens Z, Halász P (2005) Prediction of general mental ability based on neural oscillation measures of sleep. J Sleep Res 14:285-292. CrossRef Medline

Bransford J, Johnson M (1972) Contextual prerequisites for understanding: Some investigations of comprehension and recall. J Verbal Learning Verbal Behav 11:717-726. CrossRef

Brent SG (1969) Linguistic unity, list length, and rate of presentation in serial anticipation learning. J Verbal Learning Verbal Behav 8:70-79. CrossRef

Brod G, Lindenberger U, Werkle-Bergner M, Shing YL (2015) Differences in the neural signature of remembering schema-congruent and schemaincongruent events. Neuroimage 117:358-366. CrossRef Medline

Buckelmüller J, Landolt HP, Stassen HH, Achermann P (2006) Trait-like individual differences in the human sleep electroencephalogram. Neuroscience 138:351-356. CrossRef Medline

Buzsáki G (1989) Two-stage model of memory trace formation: a role for noisy brain states. Neuroscience 31:551-570. CrossRef Medline

Buzsáki G (1996) The hippocampo-neocortical dialogue. Cereb Cortex 6:81-92. CrossRef Medline

Chase WG, Simon HA (1973) The mind's eye in chess. In: Visual information processing (Chase WG, ed). New York: Academic.

Clemens Z, Mölle M, Eross L, Barsi P, Halász P, Born J (2007) Temporal coupling of parahippocampal ripples, sleep spindles and slow oscillations in humans. Brain 130:2868-2878. CrossRef Medline

De Gennaro L, Ferrara M (2003) Sleep spindles: an overview. Sleep Med Rev 7:423-440. CrossRef Medline

De Gennaro L, Ferrara M, Vecchio F, Curcio G, Bertini M (2005) An electroencephalographic fingerprint of human sleep. Neuroimage 26: 114-122. CrossRef Medline

Diekelmann S, Born J (2010) The memory function of sleep. Nat Rev Neurosci 11:114-126. CrossRef Medline

Droit-Volet S, Ramos D, Bueno JLO, Bigand E (2013) Music, emotion, and time perception: the influence of subjective emotional valence and arousal? Front Psychol 4:417. CrossRef Medline

Durrant SJ, Cairney SA, McDermott C, Lewis PA (2015) Schemaconformant memories are preferentially consolidated during REM sleep. Neurobiol Learn Mem 122:41-50. CrossRef Medline

Ego-Stengel V, Wilson MA (2010) Disruption of ripple-associated hippocampal activity during rest impairs spatial learning in the rat. Hippocampus 20:1-10. CrossRef Medline

Ellenbogen JM, Hulbert JC, Stickgold R, Dinges DF, Thompson-Schill SL (2006) Interfering with theories of sleep and memory: sleep, declarative memory, and associative interference. Curr Biol 16:1290-1294. CrossRef Medline

Ferrarelli F, Huber R, Peterson MJ, Massimini M, Murphy M, Riedner BA, Watson A, Bria P, Tononi G (2007) Reduced sleep spindle activity in schizophrenia patients. Am J Psychiatry 164:483-492. CrossRef Medline

Finelli LA, Achermann P, Borbély AA (2001) Individual "fingerprints" in human sleep EEG topography. Neuropsychopharmacology 25:S57-S62. CrossRef Medline

Fogel SM, Smith CT (2011) The function of the sleep spindle: a physiological index of intelligence and a mechanism for sleep-dependent memory consolidation. Neurosci Biobehav Rev 35:1154-1165. CrossRef Medline

Fogel SM, Nader R, Cote KA, Smith CT (2007) Sleep spindles and learning potential. Behav Neurosci 121:1-10. CrossRef Medline

Frankland PW, Bontempi B (2005) The organization of recent and remote memories. Nat Rev Neurosci 6:119-130. CrossRef Medline

Friston KJ, Holmes AP, Worsley KJ, Poline J.-P, Frith CD, Frackowiak RS (1994) Statistical parametric maps in functional imaging: a general linear approach. Hum Brain Mapp 2:189-210. CrossRef

Gais S, Mölle M, Helms K, Born J (2002) Learning-dependent increases in sleep spindle density. J Neurosci 22:6830-6834. Medline

Genzel L, Kroes MC, Dresler M, Battaglia FP (2014) Light sleep versus slow wave sleep in memory consolidation: a question of global versus local processes? Trends Neurosci 37:10-19. CrossRef Medline

Girardeau G, Benchenane K, Wiener SI, Buzsáki G, Zugaro MB (2009) Selective suppression of hippocampal ripples impairs spatial memory. Nat Neurosci 12:1222-1223. CrossRef Medline 
Hasselmo ME (1999) Neuromodulation: acetylcholine and memory consolidation. Trends Cogn Sci 3:351-359. CrossRef Medline

Johnson RE (1970) Recall of prose as a function of the structural importance of the linguistic units. J Verbal Learning Verbal Behav 9:12-20. CrossRef

Judd CM, McClelland GH, Ryan CS (2009) Data analysis: a model comparison approach. New York: Routledge.

Kerkhof GA (1991) Differences between morning-types and evening-types in the dynamics of EEG slow wave activity during night sleep. Electroencephalogr Clin Neurophysiol 78:197-202. CrossRef Medline

Lee AK, Wilson MA (2002) Memory of sequential experience in the hippocampus during slow wave sleep. Neuron 36:1183-1194. CrossRef Medline

Lustenberger C, Wehrle F, Tüshaus L, Achermann P, Huber R (2015) The multidimensional aspects of sleep spindles and their relationship to wordpair memory consolidation. Sleep 38:1093-1103. CrossRef Medline

Mandler JM, Johnson NS (1977) Remembrance of things parsed: story structure and recall. Cogn Psychol 9:111-151. CrossRef

McClelland JL (2013) Incorporating rapid neocortical learning of new schema-consistent information into complementary learning systems theory. J Exp Psychol Gen 142:1190-1210. CrossRef Medline

McClelland JL, McNaughton BL, O’Reilly RC (1995) Why there are complementary learning systems in the hippocampus and neocortex: insights from the successes and failures of connectionist models of learning and memory. Psychol Rev 102:419-457. CrossRef Medline

McDevitt EA, Duggan KA, Mednick SC (2015) REM sleep rescues learning from interference. Neurobiol Learn Mem 122:51-62. CrossRef Medline

Mednick SC, McDevitt EA, Walsh JK, Wamsley E, Paulus M, Kanady JC, Drummond SP (2013) The critical role of sleep spindles in hippocampal-dependent memory: a pharmacology study. J Neurosci 33: 4494-4504. CrossRef Medline

Minsky M (1974) A framework for representing knowledge. In: The psychology of computer vision (Winston PH, ed), pp 211-277. New York: McGraw-Hill.

Mölle M, Yeshenko O, Marshall L, Sara SJ, Born J (2006) Hippocampal sharp wave-ripples linked to slow oscillations in rat slow-wave sleep. J Neurophysiol 96:62-70. CrossRef Medline

Nishida M, Walker MP (2007) Daytime naps, motor memory consolidation and regionally specific sleep spindles. PLoS One 2:e341. CrossRef Medline

Piantoni G, Poil SS, Linkenkaer-Hansen K, Verweij IM, Ramautar JR, Van Someren EJ, Van Der Werf YD (2013) Individual differences in white matter diffusion affect sleep oscillations. J Neurosci 33:227-233. CrossRef Medline

Ramadan W, Eschenko O, Sara SJ (2009) Hippocampal sharp wave/ripples during sleep for consolidation of associative memory. PLoS One 4:e6697. CrossRef Medline

Rasch B, Born J (2013) About sleep's role in memory. Physiol Rev 93: 681-766. CrossRef Medline

Rechtschaffen A, Kales A (1968) A manual of standardized terminology, techniques and scoring system for sleep stages of human subjects. Bethesda, MD: US Department of Health, Education, and Welfare.

Rosanova M, Ulrich D (2005) Pattern-specific associative long-term potentiation induced by a sleep spindle-related spike train. J Neurosci 25:93989405. CrossRef Medline

Rumelhart DE (1980) Schemata: the building blocks of cognition. In: Theoretical issues in reading comprehension (Spiro RJ, Bruce BC, Brewer W, eds), pp 33-58. Hillsdale, NJ: Erlbaum.

Schabus M, Gruber G, Parapatics S, Sauter C, Klösch G, Anderer P, Klimesch W, Saletu B, Zeitlhofer J (2004) Sleep spindles and their significance for declarative memory consolidation. Sleep 27:1479-1485. Medline

Schabus M, Hödlmoser K, Gruber G, Sauter C, Anderer P, Klösch G, Parapatics S, Saletu B, Klimesch W, Zeitlhofer J (2006) Sleep spindle-related activity in the human EEG and its relation to general cognitive and learning abilities. Eur J Neurosci 23:1738-1746. CrossRef Medline

Schabus M, Hoedlmoser K, Pecherstorfer T, Anderer P, Gruber G, Parapatics S, Sauter C, Kloesch G, Klimesch W, Saletu B, Zeitlhofer J (2008) Interindividual sleep spindle differences and their relation to learning-related enhancements. Brain Res 1191:127-135. CrossRef Medline

Schmidt C, Peigneux P, Muto V, Schenkel M, Knoblauch V, Münch M, de Quervain DJ, Wirz-Justice A, Cajochen C (2006) Encoding difficulty promotes postlearning changes in sleep spindle activity during napping. J Neurosci 26:8976-8982. CrossRef Medline

Siapas AG, Wilson MA (1998) Coordinated interactions between hippocampal ripples and cortical spindles during slow-wave sleep. Neuron 21:1123-1128. CrossRef Medline

Sickle J (2003) Analysing correlations between stream and watershed attributes. J Am Water Resour Assoc 39:717-726. CrossRef

Sirota A, Csicsvari J, Buhl D, Buzsáki G (2003) Communication between neocortex and hippocampus during sleep in rodents. Proc Natl Acad Sci U S A 100:2065-2069. CrossRef Medline

Slotnick SD, Moo LR, Segal JB, Hart J Jr (2003) Distinct prefrontal cortex activity associated with item memory and source memory for visual shapes. Brain Res Cogn Brain Res 17:75-82. CrossRef Medline

Spoormaker VI, Schröter MS, Andrade KC, Dresler M, Kiem SA, GoyaMaldonado R, Wetter TC, Holsboer F, Sämann PG, Czisch M (2012) Effects of rapid eye movement sleep deprivation on fear extinction recall and prediction error signaling. Hum Brain Mapp 33:2362-2376. CrossRef Medline

Steriade M, Timofeev I (2003) Neuronal plasticity in thalamocortical networks during sleep and waking oscillations. Neuron 37:563-576. CrossRef Medline

Tamminen J, Payne JD, Stickgold R, Wamsley EJ, Gaskell MG (2010) Sleep spindle activity is associated with the integration of new memories and existing knowledge. J Neurosci 30:14356-14360. CrossRef Medline

Tamminen J, Lambon Ralph MA, Lewis PA (2013) The role of sleep spindles and slow-wave activity in integrating new information in semantic memory. J Neurosci 33:15376-15381. CrossRef Medline

Timofeev I, Grenier F, Bazhenov M, Houweling AR, Sejnowski TJ, Steriade M (2002) Short- and medium-term plasticity associated with augmenting responses in cortical slabs and spindles in intact cortex of cats in vivo. J Physiol 542:583-598. CrossRef Medline

Tse D, Langston RF, Kakeyama M, Bethus I, Spooner PA, Wood ER, Witter MP, Morris RG (2007) Schemas and memory consolidation. Science 316:76-82. CrossRef Medline

Tse D, Takeuchi T, Kakeyama M, Kajii Y, Okuno H, Tohyama C, Bito H, Morris RG (2011) Schema-dependent gene activation and memory encoding in neocortex. Science 333:891-895. CrossRef Medline

Ujma PP, Konrad BN, Genzel L, Bleifuss A, Simor P, Pótári A, Körmendi J, Gombos F, Steiger A, Bódizs R, Dresler M (2014) Sleep spindles and intelligence: evidence for a sexual dimorphism. J Neurosci 34:1635816368. CrossRef Medline

van Buuren M, Kroes MC, Wagner IC, Genzel L, Morris RG, Fernández G (2014) Initial investigation of the effects of an experimentally learned schema on spatial associative memory in humans. J Neurosci 34:1666216670. CrossRef Medline

van der Helm E, Walker MP (2011) Sleep and emotional memory processing. Sleep Med Clin 6:31-43. CrossRef Medline

van Kesteren MT, Fernandez G, Norris DG, Hermans EJ, Fernández G (2010a) Persistent schema-dependent hippocampal-neocortical connectivity during memory encoding and postencoding rest in humans. Proc Natl Acad Sci U S A 107:7550-7555. CrossRef Medline

van Kesteren MT, Rijpkema M, Ruiter DJ, Fernández G (2010b) Retrieval of associative information congruent with prior knowledge is related to increased medial prefrontal activity and connectivity. J Neurosci 30:1588815894. CrossRef Medline

van Kesteren MT, Ruiter DJ, Fernández G, Henson RN (2012) How schema and novelty augment memory formation. Trends Neurosci 35:211-219. CrossRef Medline

van Kesteren MT, Rijpkema M, Ruiter DJ, Fernández G (2013) Consolidation differentially modulates schema effects on memory for items and associations. PLoS One 8:e56155. CrossRef Medline

van Kesteren MT, Rijpkema M, Ruiter DJ, Morris RG, Fernández G (2014) Building on prior knowledge: Schema-dependent encoding processes relate to academic performance. J Cogn Neurosci 26:2250-2261. CrossRef Medline

Wilson MA, McNaughton BL (1994) Reactivation of hippocampal ensemble memories during sleep. Science 265:676-679. CrossRef Medline

Wixted JT (2004) The psychology and neuroscience of forgetting. Annu Rev Psychol 55:235-269. CrossRef Medline 